Supporting Information for

\title{
An Efficient Mammalian Transfer RNA Target for Bleomycin
}

Zhi-Fu Tao, Kazuhide Konishi, Gérard Keith, and Sidney M. Hecht 


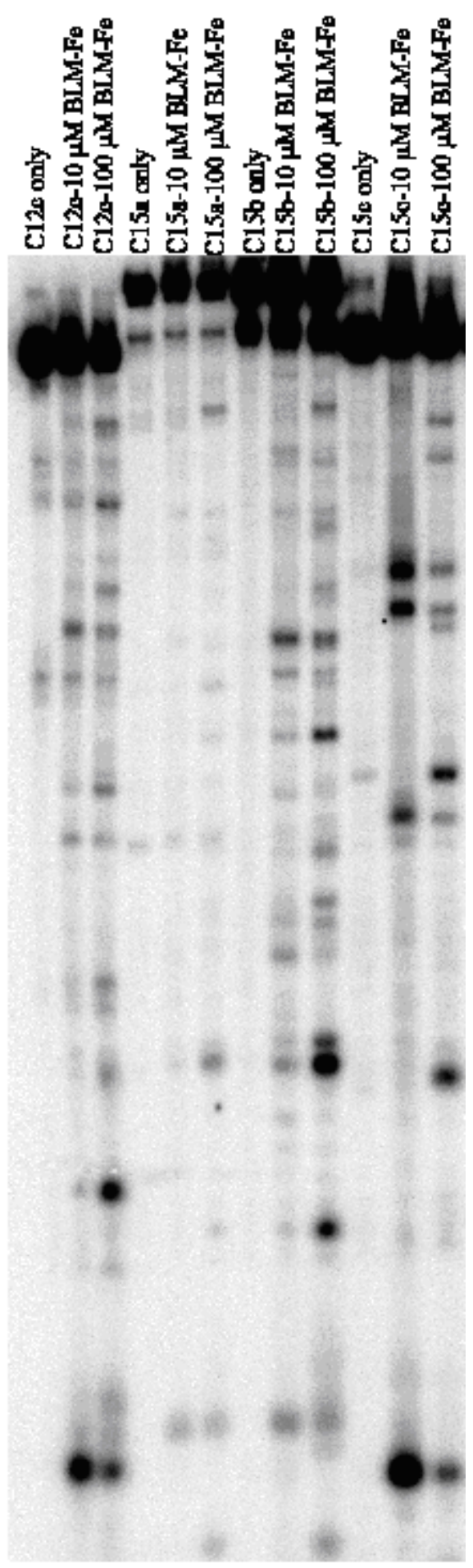

Figure S1. Chicken liver tRNA gel fractions were treated with 10 and $100 \mu \mathrm{M} \mathrm{Fe}(\mathrm{II}) \bullet \mathrm{BLM} \mathrm{A}_{5}$. ${ }^{*}$ C12c: $\boldsymbol{C}$ represents chicken, 12 represents the 12 th fraction from the BD cellulose column; ${ }^{6,7} \boldsymbol{c}$ represents band c from separation on a $10 \%$ polyacrylamide- $4 \mathrm{M}$ urea gel at $4{ }^{\circ} \mathrm{C} .{ }^{7}$ 


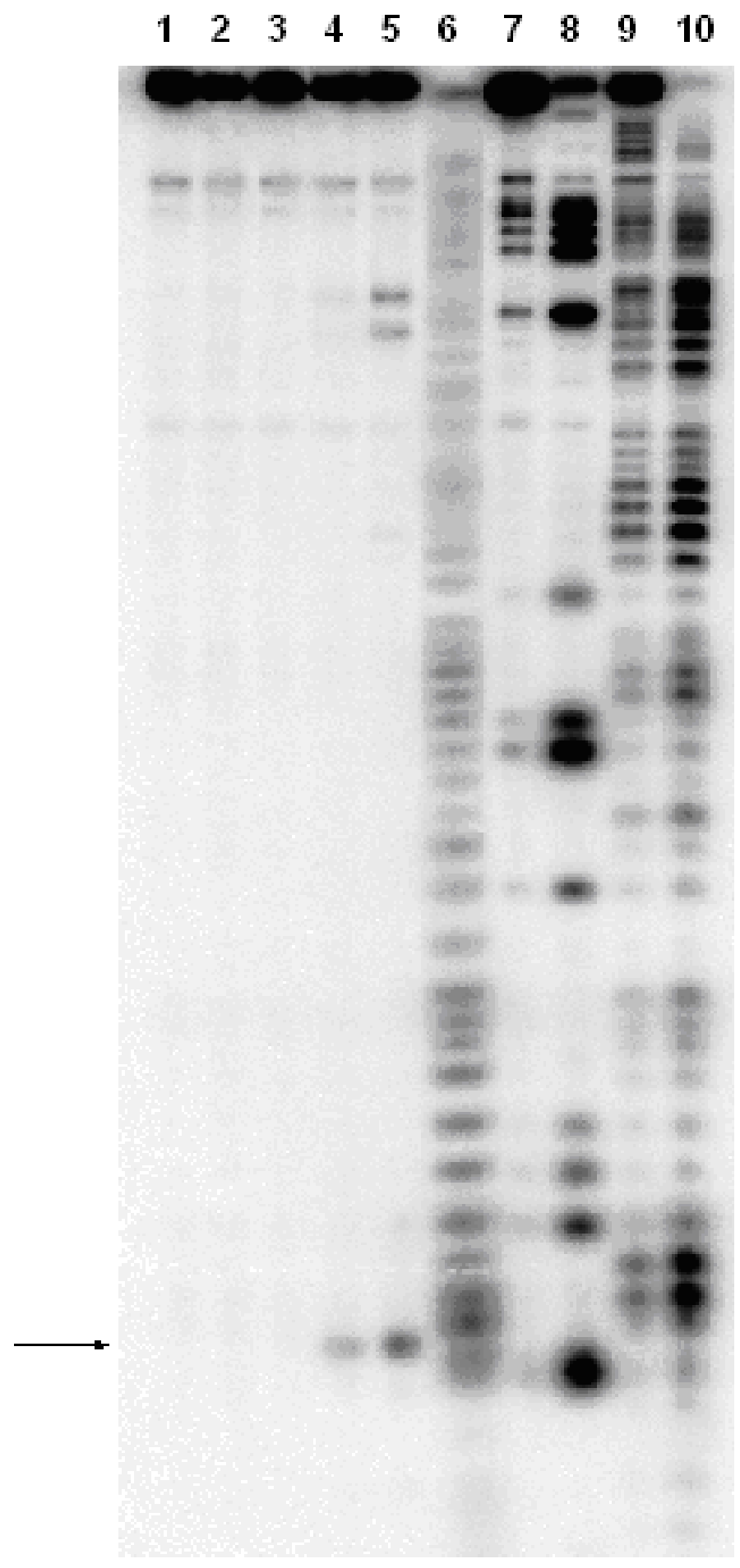

Figure S2. Chicken liver tRNA ${ }^{\text {Phe }}$ cleavage by BLM $\mathrm{A}_{5}$. [3'- $\left.{ }^{32} \mathrm{P}\right]$-labeled chicken liver tRNA $^{\text {Phe }}$ was treated with Fe(II)•BLM and then analyzed by $15 \%$ PAGE. Lane 1, RNNA $^{\text {Phe }}$ alone; lane 2, $10 \mu \mathrm{M} \mathrm{Fe}^{2+}$; lane 3, $10 \mu \mathrm{M} \mathrm{BLM} \mathrm{A}$; lane 4, $1 \mu \mathrm{M} \mathrm{Fe(II)•BLM} \mathrm{A}$; lane 5, $10 \mu \mathrm{M}$ $\mathrm{Fe}(\mathrm{II}) \cdot \mathrm{BLM} \mathrm{A}_{5}$; lane 6, aq. NaOH; lane 7, RNase T1 (G); lane 8, RNase T1 (G); lane 9, RNase $\mathrm{T} 2$; lane 10, RNase T2. 


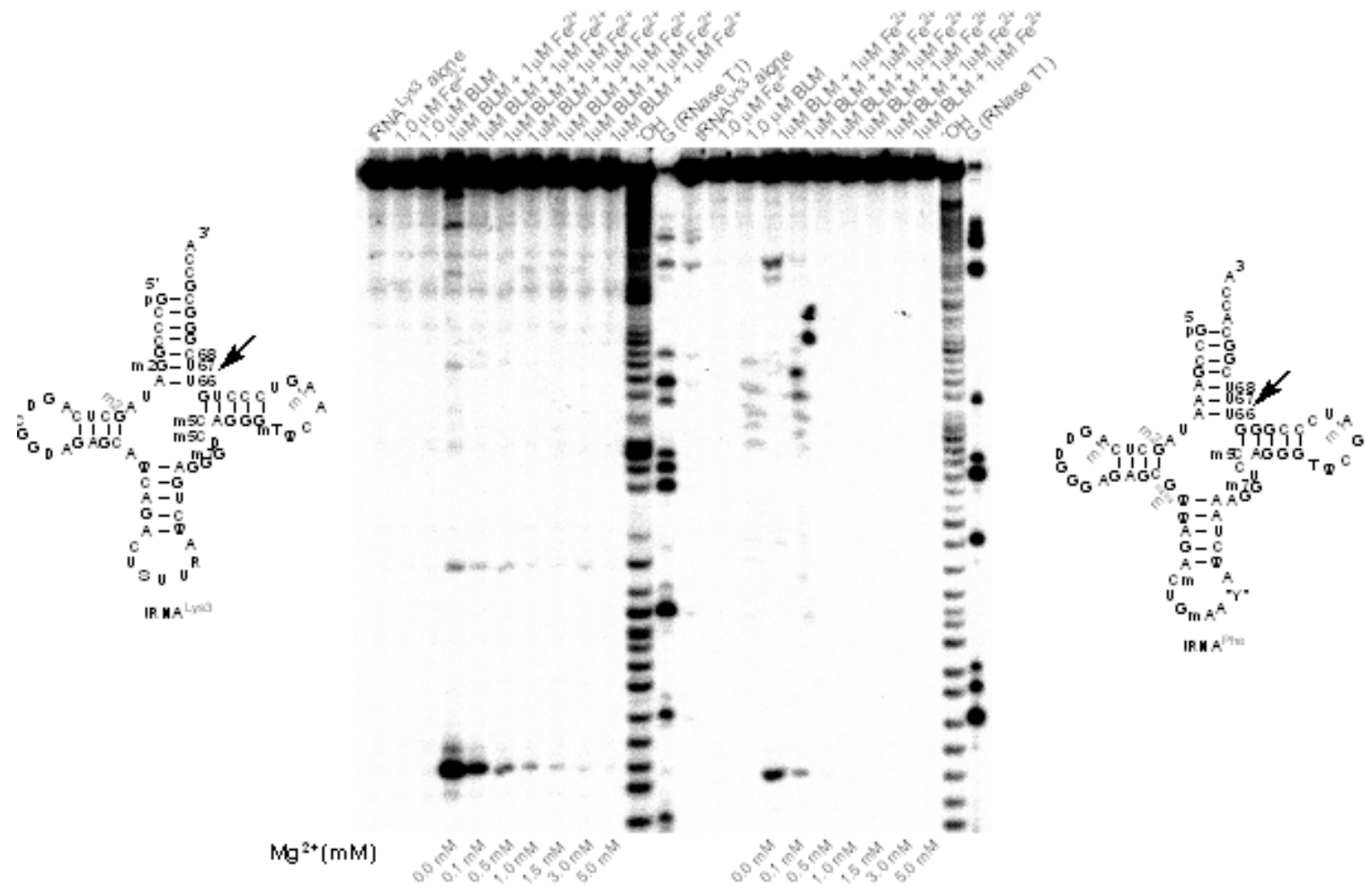

Figure S3. Effect of $\left[\mathrm{Mg}^{2+}\right]$ on the cleavage of tRNAs by Fe(II)•BLM. 